\title{
OPTIMIZING DAYLIGHT IN AN OFFICE BUILDING FOR MODERATE CLIMATE OF PUNE
}

\author{
Dhanashree Gugale \\ Master in General Architecture, MGM's Jawaharlal Nehru Engineering College, \\ Department of Architecture, Aurangabad, Maharashtra, India \\ Email-id: dhanashreegugale@gmail.com
}

\begin{abstract}
Daylight has been an immortal source of light. But currently, due to lack of resources this source is supplemented by artificial light. The illumination levels are a big contributing factor towards indoor comfort. To optimize daylight in a building, it must be oriented according to solar design. Shading, orientation, window openings are the major contributors in energy efficient building. This paper deals with the quantitative analysis of daylight through different types of openings and fenestrations used in an office building. The study is for the moderate climate of Pune. The paper also helps to understand passive design strategies like building orientation, building shape, building envelope, shading devices, etc. The analysis is done by generating simulations on software for different WWR (Window Wall Ratio), window sizes and type of glass. The strategies and guidelines for optimizing daylight in an office building are given based on the findings and results generated. Finally which type of office building design and fenestration is best suitable and can give daylight optimization without glare for a given climate is concluded.
\end{abstract}

Key words: polypropylene fibres, Deformed steel fibres, Catastrophic failure, impact resistance, compressive strength, flexure and tensile strength.

Cite this Article: Dhanashree Gugale, Optimizing Daylight in an Office Building for Moderate Climate of Pune, International Journal of Advanced Research in Engineering and Technology, 10 (3), 2019, pp 203-216.

http://iaeme.com/Home/issue/IJARET?Volume $=10 \&$ Issue $=3$

\section{INTRODUCTION}

In India among all the building typologies, energy consumption is maximum in commercial buildings. The energy is mainly utilized for lighting the interiors and cooling the building. Lighting and cooling the building again generates heat inside and around the building which in turn increase cooling load. A study shows that about $20-40 \%$ energy is consumed for lighting, out of the total electricity required for a building.

Harvesting daylight can significantly reduce electricity consumption in a building. However it also require to counter balance the heat gain or heat loss, glare, variation, etc. Many offices 
use light photo sensors which take advantage of daylight and dimming light so that no more light is produced than necessary. This can improve productivity of an employee and make him comfortable and efficient.

As the cost of energy increases, efforts are made to minimize energy consumption. This can be done by- utilization of daylight in design practice. It is very comfortable to work in natural light than artificial light but excessive daylight can even create glare problem for users.

Index terms: Daylight, office building, energy efficient, illumination level, shading.

\section{LITERATURE REVIEW}

A building envelope protects the building from the external environment. This envelope includes roof, external façade, projections, etc. which act as thermal shell and decides the temperature intake inside the building. In moderate climate there is not much variation in average yearly temperature as the temperature do not reach the extreme levels. The design in such climatic zone can be flexible enough and efforts should be made to reduce heat gain and maintain thermal comfort level.

Shading, building orientation, windows, openings and their sizes are the major contributors in making the building energy efficient.

The daylight penetration inside the room in a working space is an important factor as it influences users ability to have outdoor view and the design of electrical lighting system. For this the daylight should cover maximum room depth by maintaining required lighting levels. According to one of the developed methods, if the depth of the space increases and is more than three times the ceiling height, the daylight factor (DF) in deeper parts of the room might decrease below $1 \%$.[9]

The recommended illumination levels on a working plane in an office is 300-750 lux.

Illumination levels for different task are recommended to be achieved either by day lighting or artificial lighting or a combination of both. [10]

Table 1 IES standard illumination and MS 1525 recommendation for different office spaces

\begin{tabular}{|c|c|c|}
\hline SPACE & $\begin{array}{c}\text { IES STANDARD } \\
\text { ILLUMINATION (lux) }\end{array}$ & $\begin{array}{c}\text { MS 1525 } \\
\text { RECOMMENDATION (lux) }\end{array}$ \\
\hline General offices & 500 & $300-400$ \\
\hline Computer room & 500 & $300-400$ \\
\hline Conference room & 750 & $300-400$ \\
\hline Executive office & 500 & $300-400$ \\
\hline Filing room & 300 & 200 \\
\hline Print room & 300 & $300-400$ \\
\hline
\end{tabular}

Optimization of daylight mainly depends on passive solar heat gain elements, position and orientation of building and percentage of glazing. Passive building design methods mainly include

- Orientation

- Building shape

- Ratio of wall to window

- Envelopes and Shading devices 
All perimeter parts of buildings lying within $6 \mathrm{~m}$ of the facade, or twice the ceiling height, are classified as passive, while rest of the other zones are considered non-passive (Fig 1).


Figure 1 Parts of building that can be naturally lit and ventilated are called passive zones [6]

Strategies for maintaining thermal comfort and energy efficiency in a building have to be incorporated at design stage. One of these could be passively design envelopes which actively meet heating and cooling needs of building. Building envelope provide thermal division between indoor and outdoor as well as play an important role in determining how effectively natural light can be utilized in a building.

The research is about which type of window opening and their percentage are best suitable for office building to achieve optimization of daylight in moderate climate(of Pune).

\section{METHODOLOGY}

\section{Steps}

- Comparison of different types of window openings considering their sizes, projections, shading devices, etc (grid of the building block will be same in each case) in IT office building.

- Designing and orienting them in suitable direction during daytime for two months and analyzing with the help of simulations (May and December)

- Considering WWR same in all the cases maintaining a suitable sill level $0.8 \mathrm{~m}$.

- Observing outputs of different simulations

- Concluding the results and observations

\section{Case studies}

- $\quad$ KPIT, Pune (window with shading fins)

- TCS, Chennai (ribbon window)

- Infosys, Pocheram (window with shading fins and light shelf)

\section{UNIT DESIGN FOR SIMULATIONS}

\subsection{Building Shape}

To check which type of shape /form is suitable for office building in moderate climate of Pune, three different forms are considered viz. circle, square and rectangle. The floor plate area is maintained same in all the cases. Daylight simulations are carried out annually orienting the buildings in N-S direction and keeping WWR ratio 40\%. 
Table 2 Daylight simulations for different building forms

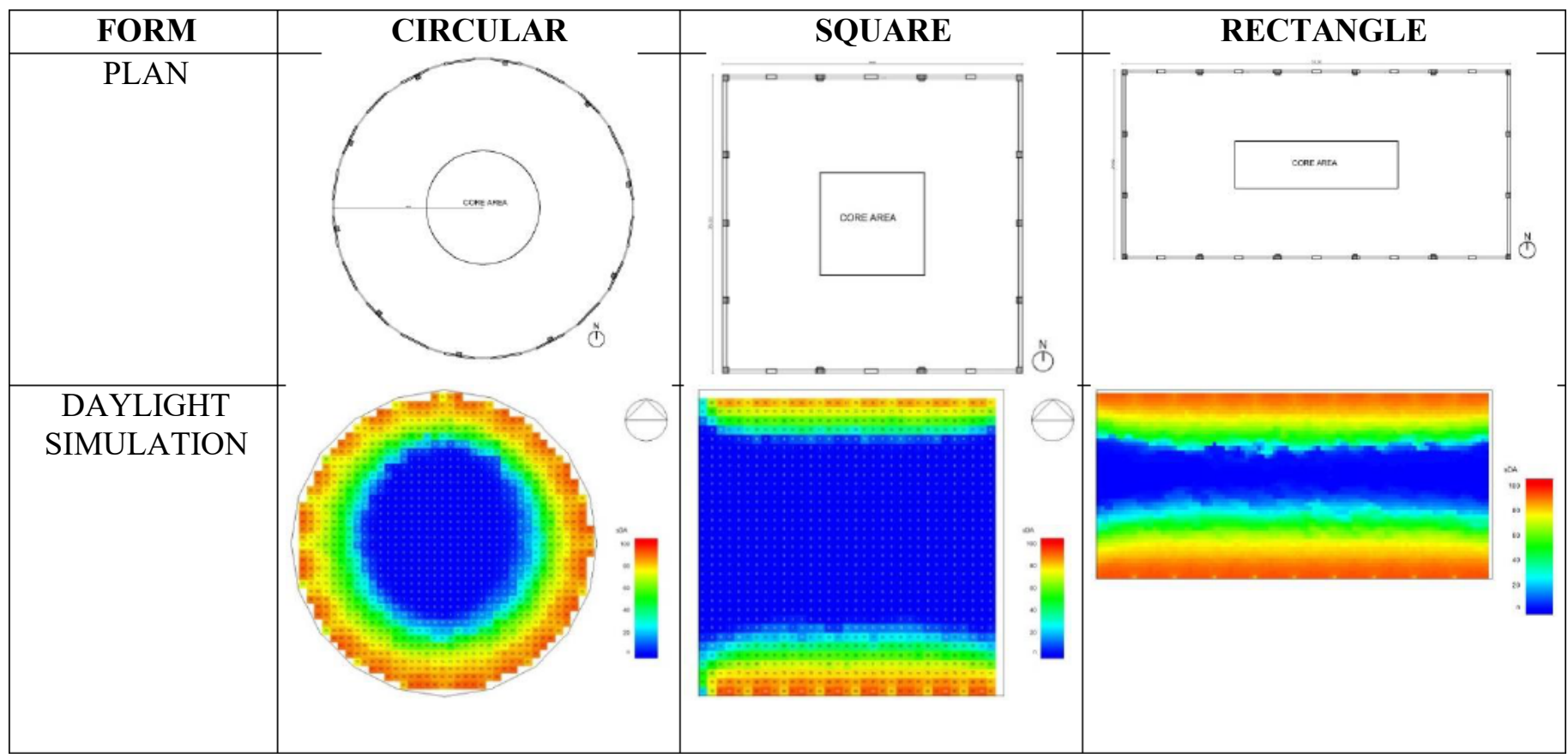

It is found that the illumination level is more in rectangular form than circular or square form.

\subsection{Window Openings}

An office building of floor plate $50 \mathrm{~m} \times 24 \mathrm{~m}$ and height $4.2 \mathrm{~m}$ with central core area is considered as a base module. Same grid is maintained to carry out daylight simulations in seven cases for different window openings. The building block is oriented in N-S direction and openings are provided on same faces. The results are analyzed using Design Builder as simulation software. The WWR is same in all the cases i.e 40\% (as per ECBC code). The wall, floor and ceiling reflectance is kept constant in all the cases. The sill height is maintained at $0.8 \mathrm{~m}$. The cases have been simulated for the month of May (summer) and December (winter) and are generated for clear sky conditions. The target task illuminance is set to 300lux. In simulation model the windows are specified with aluminum framing with a single glazed unit having a glass of transmittance value 0.62 the readings are analyzed for lux level 20 to 1000 .

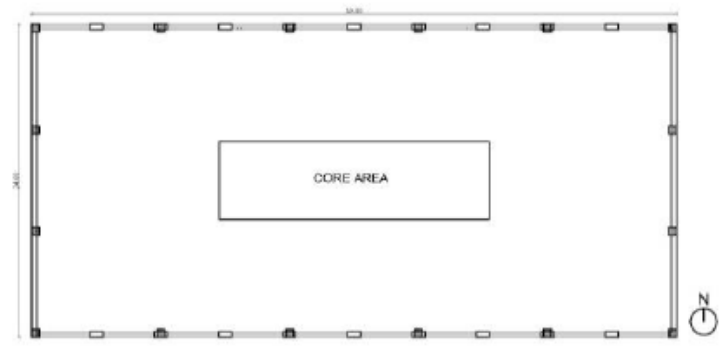

Figure 2 Office building floor plan considered for simulations

Table 3 Types of window considered for simulation

\begin{tabular}{|c|l|}
\hline CASES & \multicolumn{1}{|c|}{ WINDOW TYPE } \\
\hline Case 1 & Box Window \\
\hline Case 2 & Window with overhang \\
\hline
\end{tabular}


Optimizing Daylight in an Office Building for Moderate Climate of Pune

\begin{tabular}{|c|l|}
\hline Case 3 & Ribbon window with overhang \\
\hline Case 4 & Ribbon window with column spacing \\
\hline Case 5 & Window with light shelf \\
\hline Case 6 & Window with shading fins \\
\hline Case 7 & Window with shading fins and light shelf \\
\hline
\end{tabular}

\subsubsection{CASE 1: Box Window}

It is observed that for every $1 \mathrm{~m}$ distance from window the illumination level gradually decreases. In the month of May and December a sufficient amount of daylight can penetrate only upto $3 \mathrm{~m}$ from the window line. The rest of the office area will have to depend on artificial light.

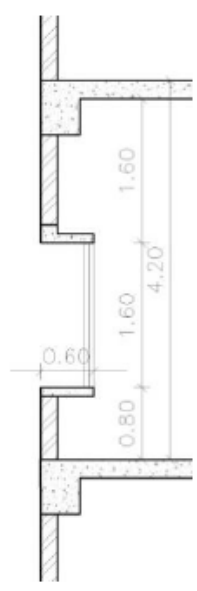

Figure 3 Section of Box window

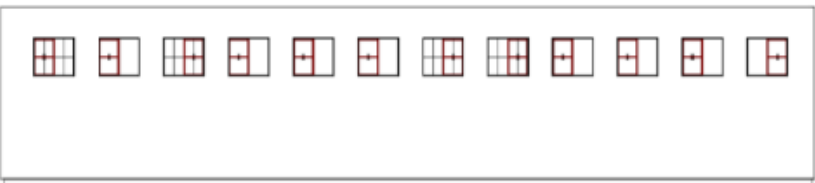

Figure 4 Building elevation with box wind

Table 4 Day light simulation for box window

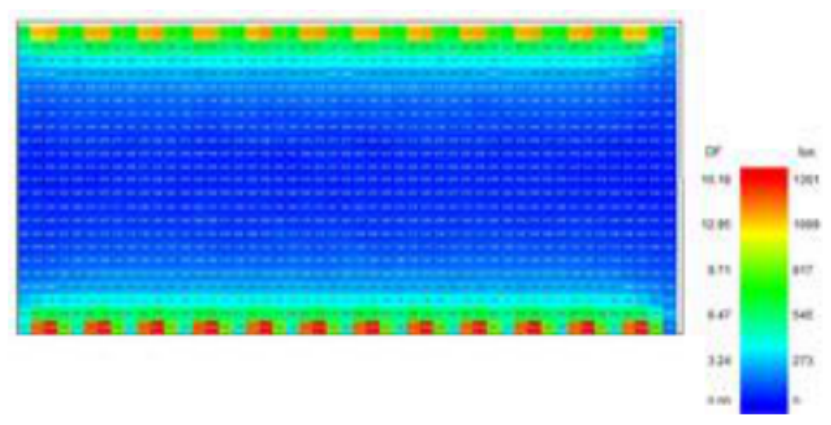

Day light simulation for month of May 


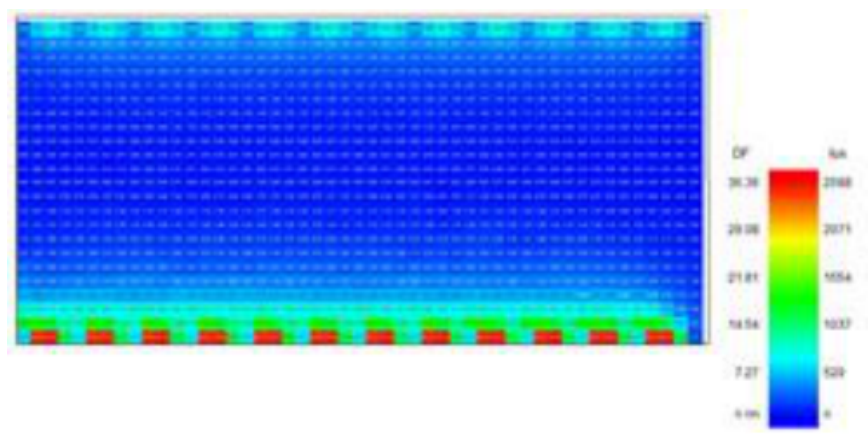

Day light simulation for month of December

\subsubsection{CASE 2: Box Window with Overhang}

There is a decrease in illumination level for every $1 \mathrm{~m}$ from the window line. The illumination level is slightly more than case 1 . Maximum illumination of 900lux is achieved at $1 \mathrm{~m}$ distance from the window. In both months about 300lux level is achieved upto $4 \mathrm{~m}$ distance from the window.

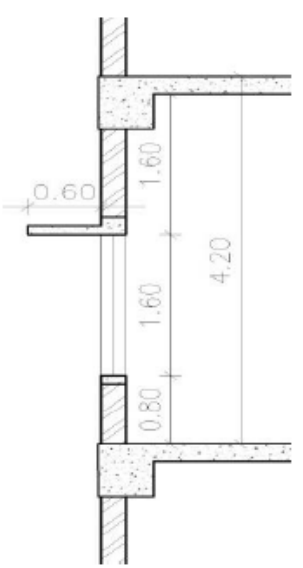

Figure 5 Section of Overhang window

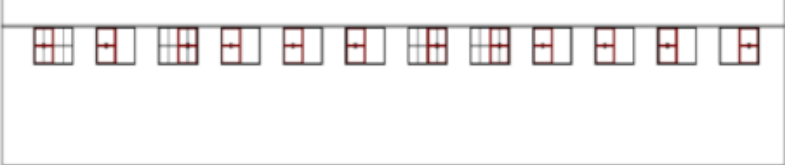

Figure 6 Building elevation with overhang window

Table 5 Day light simulation for box window with overhang

Day light simulation for month of May

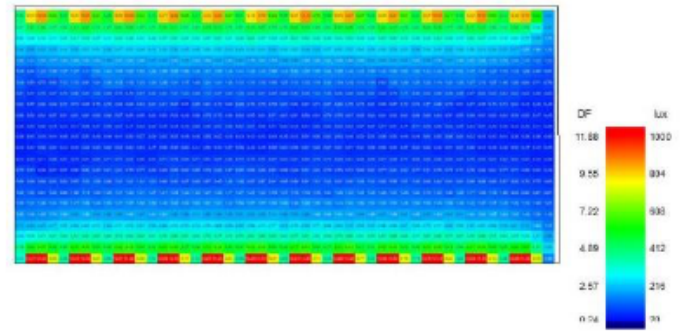


Day light simulation for month of December

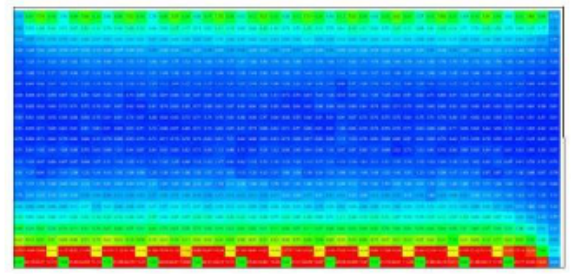

\subsubsection{CASE 3: Ribbon Window with Overhang}

In this case it is observed that about $3001 \mathrm{ux}$ is achieved up to $5 \mathrm{~m}$ from the window for both the months and gradually decreases at the center. The illumination levels are quite more in this case than Case 2. As the opening size increases the illumination level increases.

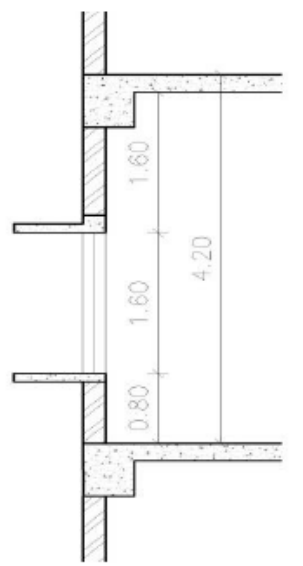

Figure 7 Section of ribbon window with overhang



Figure 8 Building elevation with ribbon window

Table 6 Day light simulation for ribbon window with overhang

Day light simulation for month of May

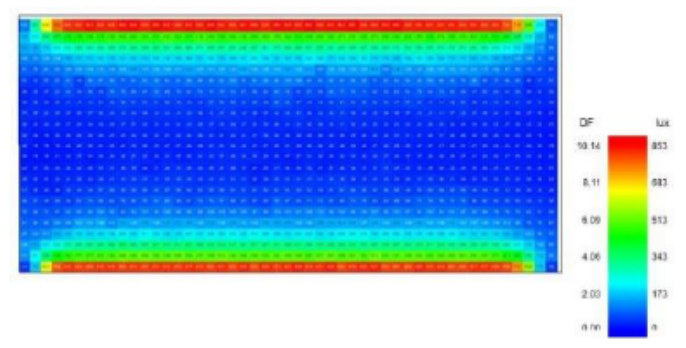


Dhanashree Gugale

Day light simulation for month of December

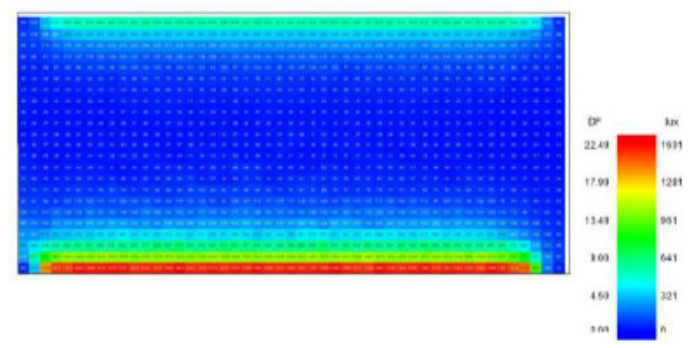

\subsubsection{CASE 4: Ribbon Window with Column Spacing}

In this case it is observed that daylight optimization is more than the earlier cases. Here the columns act as shading device for the ribbon windows and hence more diffused light can penetrate. About 300lux is achieved up to $6 \mathrm{~m}$ in both months.

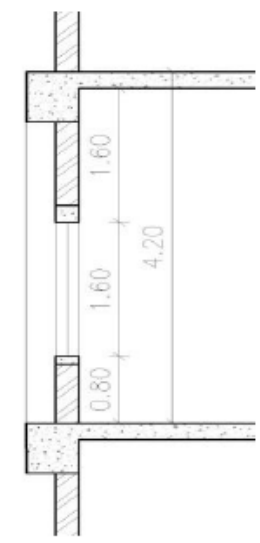

Figure 9 Section of ribbon window with column spacing

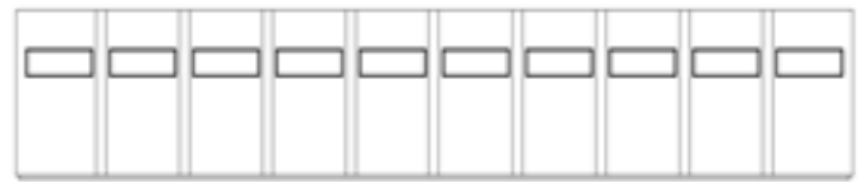

Figure 10 Building elevation with ribbon window and column spacing

Table 7 Day light simulation for ribbon window with column spacing

Day light simulation for month of May

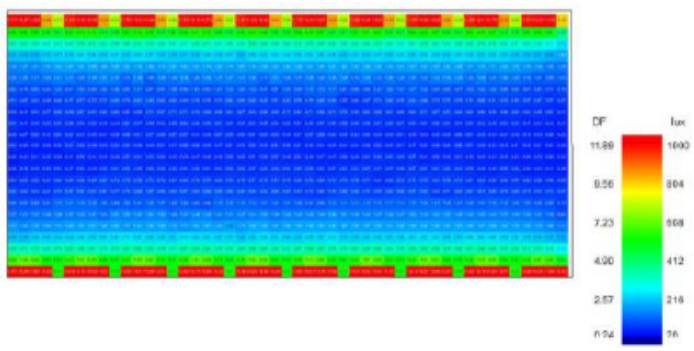


Optimizing Daylight in an Office Building for Moderate Climate of Pune

Day light simulation for month of December



\subsubsection{CASE 5: Box Window with Light Shelf}

In this case the daylight penetration is less than case 4 . The use of light shelf do not increase the light levels in this case. Daylight penetration is about 300lux upto $4 \mathrm{~m}$ in the month of May while it is 400 lux upto $4 \mathrm{~m}$ only from south side in the month of December.

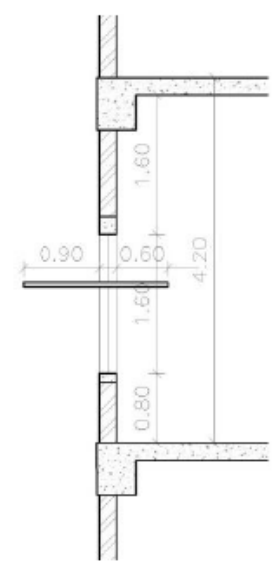

Figure 11 Section of box window with light shelf

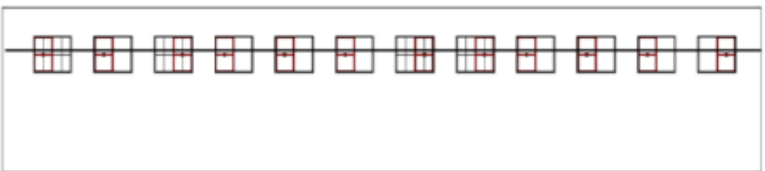

Figure 12 Building elevation with box window and light shelf

Table 8 Day light simulation for box window with light shelf

Day light simulation for month of May

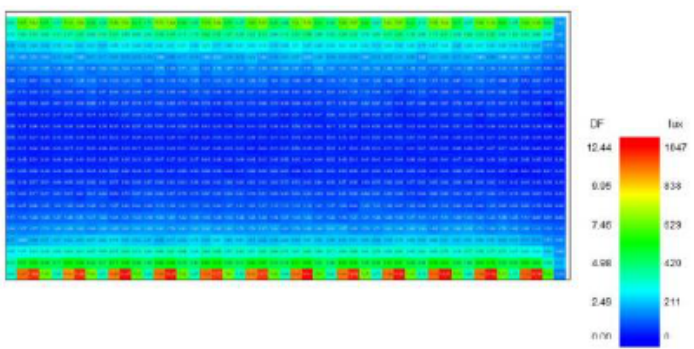


Dhanashree Gugale

Day light simulation for month of December

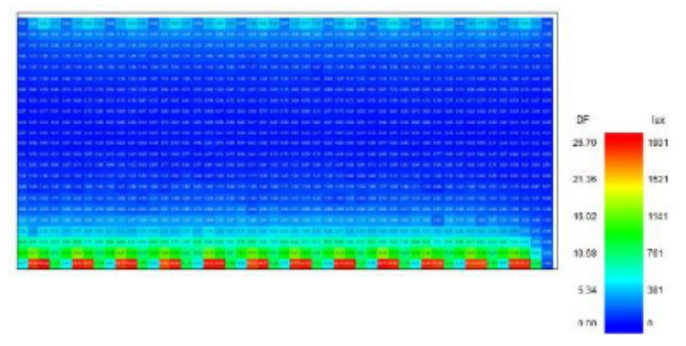

\subsubsection{CASE 6: Window with Shading Fins}

In this case the illumination levels are maximum than the above cases. About 300 lux is achieved up to $6-7 \mathrm{~m}$. The shading fins allow more diffused light to penetrate inside the room.

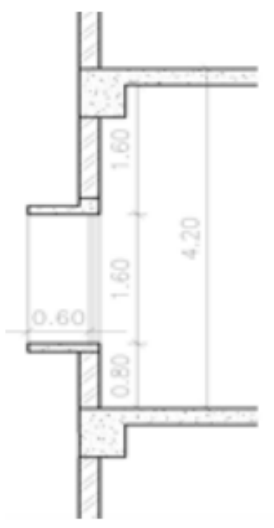

Figure 13 Section of window with shading fin



Figure 14 Building elevation with window and shading fins

Table 9 Day light simulation for window with shading fins

Day light simulation for month of May



Day light simulation for month of December

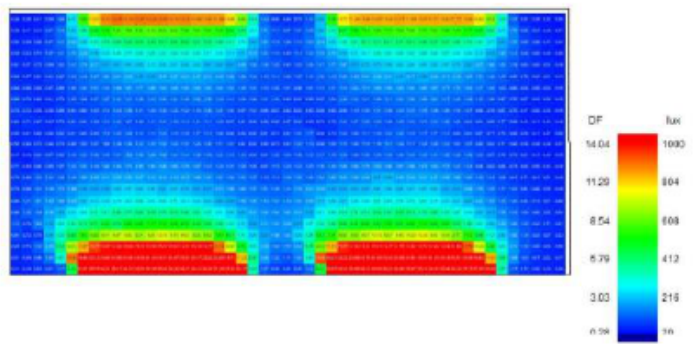




\subsubsection{CASE 7: Window with Shading Fins and Light Shelf}

In this case the illumination levels are similar to case 6 . About 300 lux is achieved up to $6-7 \mathrm{~m}$. The addition of light shelf do not increase daylight penetration in the room. It only diffuses the light near window and provides shading in the lower part near the window.

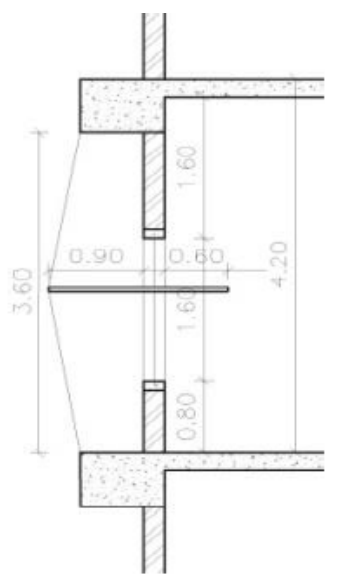

Figure 15 Section of window with shading fins and light shelf

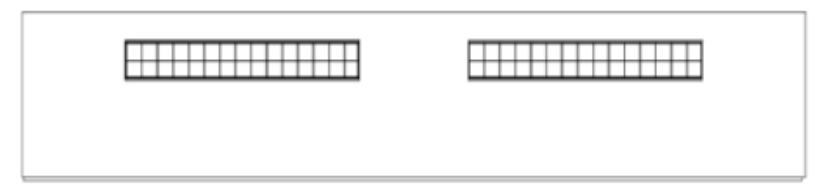

Figure 16 Building elevation with shading fin windows and light shelves

Table 10 Day light simulation for window with shading fins and light shelf

Day light simulation for month of May

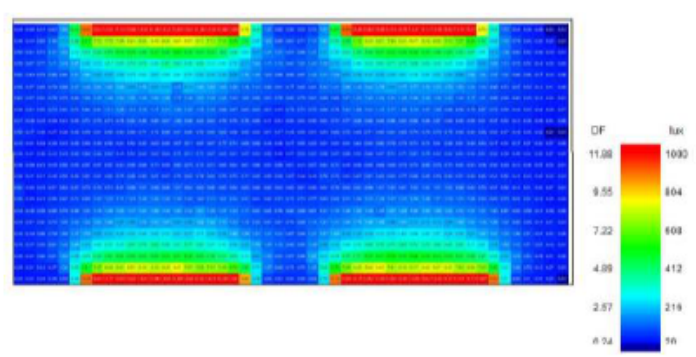

Day light simulation for month of December



The illumination levels in case 6 and case 7 are maximum than case 1 to case 5 , hence annual day light simulations are carried out to find out which case is most appropriate. 


\subsubsection{Annual Result for Case 6 and Case 7}

Table 11 Annual illuminance for window with shading fins (only) and window with shading fins and light shelf

Case 6: Annual illuminance


Case 7: Annual illuminance
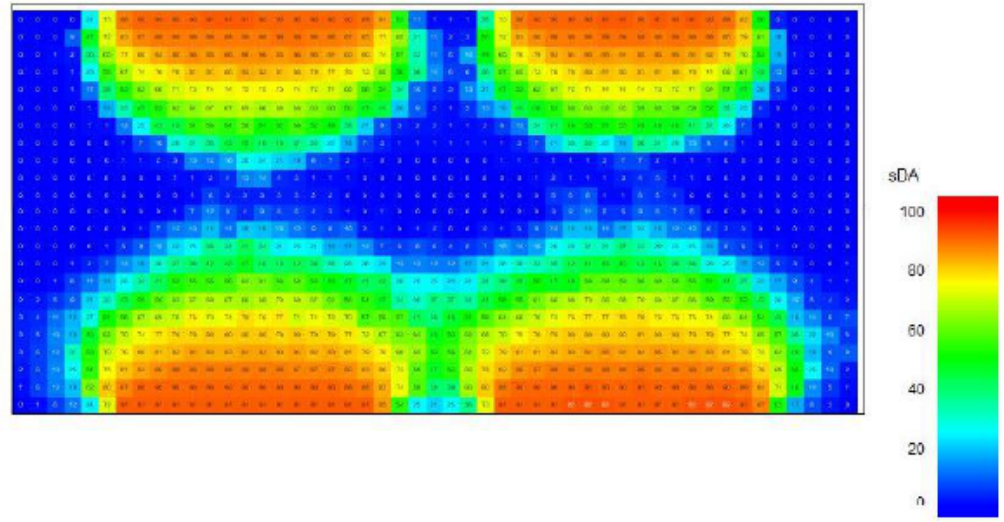

The annual daylight simulations show that in case 6 the daylight penetration is deeper and reaches till the center of the room. About 300lux is achieved at the center

\section{RESULTS}

Table 12 Illumination in month of May and December for different types of window.

\begin{tabular}{|c|l|c|c|}
\hline Cases & \multicolumn{1}{|c|}{ Window type } & $\begin{array}{c}\text { Illumination in month of } \\
\text { May (>300lux) }\end{array}$ & $\begin{array}{c}\text { Illuminance in month of } \\
\text { December ( >300lux) }\end{array}$ \\
\hline Case 1 & Box Window & $42 \%$ & $29 \%$ \\
\hline Case 2 & Window with overhang & $50 \%$ & $50 \%$ \\
\hline Case 3 & Ribbon window with overhang & $50 \%$ & $29 \%$ \\
\hline Case 4 & $\begin{array}{l}\text { Ribbon window with column } \\
\text { spacing }\end{array}$ & $55 \%$ & $55 \%$ \\
\hline Case 5 & Window with light shelf & $45 \%$ & $33 \%$ \\
\hline Case 6 & Window with shading fins & $56 \%$ & $61 \%$ \\
\hline Case 7 & $\begin{array}{l}\text { Window with shading fins and } \\
\text { light shelf }\end{array}$ & $48 \%$ & $58 \%$ \\
\hline
\end{tabular}




\section{MEASURES TO CONTROL GLARE}

Following are the measures which can be adopted to control glare in an office building:

- The reflected glare from the extremely bright exterior surfaces like large paving or sand area, parked cars, can be visually uncomfortable. The view of these surfaces must be limited or protected.

- A light-color shade can be used for interiors to minimize heat gain.

- Fine screens which reduce illumination and glare can be used for shading the window to maintain an exterior view without any obstruction. Louvers or screens that operate upward from the window sill can also be used.

\section{CONCLUSION}

Every building component has potential for saving energy hence it must be chosen properly. The illumination levels are more in rectangular form office building for moderate climate of Pune. The increase in wall window ratio (WWR) increases daylight penetration but also rises the heat levels in the building. Hence low WWR is recommended i.e $<40 \%$. Double skin glazing with low U-value should be used. Day light enhancement system such as light shelves do not improve daylight levels (in Pune) significantly but shades the lower part of the window and thereby reducing cooling loads in summer. The shading fins can be used to increase the amount of daylight in an office.

\section{REFERENCES}

[1] CPWD. A handbook for planning of office buildings. New Delhi : Directorate General, CPWD, 2013

[2] KRISHAN, A. Climate Responsive Architecture: A design Handbook for Energy efficient Buildings. New Delhi: Tata McGraw Hill. (2001)

[3] CBRI Solar Data Book, Roorkee: Central Building Research Institute, (1968)

[4] ECBC. Energy Conservation Building Code User Guide. New Delhi: Bureau of Energy Efficiency, 2011.

[5] Komal Thakur, K.P. Rewatkar, Energy Optimisation in Office Buildings Through Daylighting Design for Climatic Conditions of Central India. (2015) Available from: http://dspace.chitkara.edu.in/jspui/bitstream/1/747/3/32009_CS_Komal\%20Thakur.pdf

[6] Meishun Lin1, Yiqun Pan, Weiding Long, Weizhen Chen, Influence of Building Shape Coefficient on Energy Consumption of Office Buildings in Hot-Summer-and-Cold-Winter Area of China (2014). Available from:

http://ibpsa.org/proceedings/asim2014/160_AsimC5-29-293.pdf

[7] Farheen Bano, Mohammad Arif Kamal, Examining the Role of Building Envelope for Energy Efficiency in Office Buildings in India. (2016) Available from: https://www.academia.edu/30472968/Examining_the_Role_of_Building_Envelope_for_E nergy_Efficiency_in_Office_Buildings_in_India_Article_Outline [Accessed on: 23 March 2019]

[8] Bengali, Abdulkader, Developing Energy Efficient Building Envelope. (2009)

[9] DeKay, M., Brown, G.Z., Sun, Wind, and Light: Architectural Design Strategies, third edition. ed. Wiley, Hoboken. (2014) 


\section{Dhanashree Gugale}

[10] Room Illumination Levels. Available from:

http://www.pioneerlighting.com/new/pdfs/IESLuxLevel.pdf [Accessed on: 28 March 2019]

[11] Badri Narayan Mohapatra, M. Ravi Kumar and Sushant K. Mandal, Analysis of Daylighting Using Daylight Factor and Luminance for Different Room Scenarios, International Journal of Civil Engineering and Technology, 9(10), 2018, pp. 949-960. 